\title{
Fostering 4.0 Workforce: A Case Study of Business-Engineering Integration Project
}

Pichayalak Pichayakul

Faculty of Business Administration, Chiang Mai University, Chiang Mai 50200, Thailand

Correspondingauthor.E-mail:pichayalak@gmail.com

https://doi.org/10.12982/CMUJASR.2019.0009

\section{ABSTRACT}

This study aims to determine how to foster workforce 4.0 attributes to university students. Workforce 4.0 attributes consist of cognitive and physical abilities, process and system skills, content and social capabilities, problem solving abilities, technical aptitude, and efficient resource management The researcher uses Communication for Business Result Course (in which she is the instructor) as a case study. She applies design thinking concept in the learning process throughout the course. The target population of this study consists of students registered in this course. As the researcher intends to deeply understand the students'experiences, attitudes, and interactions, qualitative research methods were applied The sample consisted of four students who worked in the same team on a business-engineering integration project in this course. The researcher gathered data through participant observation along with in-depth interview. In addition, the researcher applied quantitative methodology by using structured questionnaire as an additional tool to retrieve measurable degree of the students'workforce 4.0 attributes that compares before and after working on this project. The interview, as well as the questionnaire, are used as a form of cross-checking information or so called triangulation, in order to ensure that the data accurately depicts the samples' feedback and the accuracy of conclusions drawn from the data. The results indicate that the integrated pedagogy of designing thinking and projectbased approaches resulted in successful fostering of the nine 4.0 workforce attributes among the students. This integrated pedagogy could be a model to develop workforce 4.0 for the Higher Education System.

Keywords: Integration project based learning, 4.0 workforce, Thai University students.

\section{INTRODUCTION}

The global workplace is dramatically changing due to the impacts of the fourth industrial era. The fourth industrial revolution shifts the industry process from automated factory to intelligent and integrated digital systems. A study by Deloitte, the world-renowned multinational professional services network, forecasted that from 2018 to 2028, up to 4.6 million industrial jobs will be created. However, around half of those new jobs have potential to be unfilled due to the 
insufficient number of qualified personals (Deloitte, 2020). Furthermore, the commercial aspect also changes from person to person to on-line platform. Consequently, the market changes its demand for workforce qualifications. The National Association of Manufacturers (NAM) forecasts that approximately 80 percent of manufacturers are particularly in need of qualified employees who possess ability to meet customer demand, innovate, develop new products, and the capabilities to cope with the disruptive world (Stackpole, 2019). The significance changes in human resource qualifications demand a response from educational institutions. Higher education shall take responsibility in this new era by preparing the next generation to enter the industrial world (Johnson, 2020).

This paper showcases a way to foster the next generation workforce by deploying a business-engineering integration project in Communication for Business Results course. In this course, the students learn how to communicate for innovative business development, to build teams, to conduct target market analysis survey, and to analyze business data. Throughout the course, the students are assigned the development of a business project starting from developing an innovative idea to test target market and finally to constructing a business model. The students have to review a number of related business articles, to observe, to talk to people and to discuss in teams to come up with a rationale innovative business model proposal (Communication for Business Results syllabus, 2019). The results of this study shall provide practical suggestions to develop workforce 4.0 for the Higher Education System.

\section{LITERATURE REVIEWS}

\section{Workforce 4.0}

According to Workforce Blueprint, 2017, Workforce 4.0 consists of 9 attributes including 1) cognitive ability 2) physical ability 3) process skill 4) system skill 5) content capability 6) social capability 7) problem solving ability 8) technical aptitude and 9) efficient resource management. Each attribute can be explained as follows. First, according to Michelon (2006), cognitive ability is the aptitude of a person to understand the world and act in it properly. Second, physical ability refers to the individuals' capabilities to perform works in which they have to apply physical skill (U.S. Office of Personnel Management, 2020). Third, process skill presents ways of thinking about and interacting with situations that can lead to an understanding of new ideas and concepts. With process skill, learners can gather information, test their ideas, and construct explanations logically (Institute for Inquiry, 2006). Fourth, system skill, the learners should be able to explain how a system works and how changes in the work environment will has impact on the outcomes (Awasthi, 2010). Fifth, content capability is a strategic marketing approach emphasizing on generating valuable and appealing content to attract and retain target audiences (Content Marketing Institute, 2020). Sixth, social capability, refers to the ability to develop good interpersonal relationships as well as to construct leadership skills (Australian Curriculum, 2020). Seventh, problem solving ability, refers to the capability to cope with difficult or unexpected situations and able to solve the problems effectively (Indeed Career Guide, 2020). Eighth, technical aptitude is the ability and knowledge needed to work on particular tasks. Technical aptitude is necessary for practical and technical tasks such as information technology and mathematical related tasks (Doyle, 2019). Ninth, resource management is the skills to obtain, designate, and utilize internal and external resources efficiently (Bird, 2018). 


\section{Teaching strategies}

There are several teaching strategies that are widely implemented in the higher education institutes. In this research, 3 prominent strategies were applied: 1) Project Based Learning 2) Cooperative Learning and 3) Devil's Advocate Questioning Technique. Firstly, Project Based Learning $(\mathrm{PBL})$ is a student-oriented teaching methodology in which the teachers perform as facilitators in the class. Learners pursue knowledge by asking questions based on their interests and curiosity. PBL technique is usually applied to create active thinkers and learners. Learners work on the real-world cases by designing their own inquiries from their perspectives, then research for information and make a plan to solve the problems. In the learning process, the learners shall implement various learning strategies. The outcomes of $\mathrm{PBL}$ are deeper understanding of the topic, elevated reading skills, and amplified motivation to learn (Bell, 2010). Secondly, Cooperative Learning is a systematic instructive strategy that inspires small groups of learners to work together toward a common goal. This means the learners will be assigned to work in a group. This strategy, in principle, would highly stimulate learners' discussions. To perform well in the class, the learners should be able to work in a team by leading, compromising, and listening to the others (George Mason University, 2019). Lastly, Devil's Advocate Questioning Technique involves developing a solid argument or a critical question to help another person think thoroughly. This technique is widely used in the business sector. In addition, this idiomatic expression is used to express the concept of arguing against something without actually being committed to the contrary view. The learners understand that the questions are to help them think, not to simply to challenge them irrationally (Hartwig, 2019).

\section{Design thinking process}

Design thinking is a learning methodology that provides a non-linear and iterative process to solve problems. It is usually used to decipher complex problems that are vaguely defined or unknown. Hasso-Plattner Institute of Design at Stanford (d.school) elaborates the five-stage of design thinking model as follows. 1) Empathize or gain an understanding of the problem. This stage could be done through observing, engaging, and empathizing with people to understand the situation. 2) Define the problem. During this stage, a person shall analyze and synthesize information gathered from earlier stage to define the core problem. 3) Ideate for solutions. In this stage, one should formulate solutions to the problem as well as indicate resources needed. 4) Develop prototype. Prototype is an inexpensive, scaled down versions of the product. This is an experimental phase in order to assess the users' feedback on whether they will accept, reject, or make suggestions for improvement. 5) Test. This stage is to test the complete product and to understand the product users' needs as much as possible (Interaction Design Foundation, 2020; Dam \& Teo, 2020). The researcher structured the assessment of workforce 4.0 attributes of this study based on the definition given by the aforementioned Workforce Blueprint (2017). The assessment results are presented in part 3 of the results section. The 3 teaching strategies and the 5 stages of design thinking process are applied to develop the learning process of the Communication for Business Results course in which the researcher used as a case study for this research. The 5 main phases of the learning process throughout the course are reported in Part 2 of the result section. 


\section{MATERIALS AND METHODS}

This research was conducted in a Communication for Business Result course which is offered by the Faculty of Business Administration at Chiang Mai University. The data collection period was in the first semester of academic year 2019 (August-December, 2019). The researcher adopted quantitative methods in conjunction with qualitative methodologies. The integration of qualitative and quantitative studies enhances the ability to add a new aspect to interventional studies that cannot be obtained through measurement of variables alone (Pathak, Jena and Kalra, 2013).

As the researcher intends to deeply understand the students' experiences, attitudes, and interactions, it was decided to focus on a small number of 5 informants. The use of purposive sampling method allowed for specifically selecting 4 students who worked in the same team on a business-engineering integration project in this course. The researcher gathered data through participant observation along with in-depth interviews. The participant observation method was utilized to gain a close familiarity with the samples in this study through an intensive involvement over an extended period of time. In addition, the researcher applies quantitative methodology by using structured questionnaire as an additional tool to retrieve measurable degree of the students' workforce 4.0 attributes that compares before and after working on this project. The interviews, as well as the questionnaire, are used as a form of cross-checking information or so called triangulation in order to ensure that the data is accurately depicting the samples' feedback and the accuracy of conclusion drawn from the data.

\section{RESULTS}

The results are reported in 4 parts as follows.

\section{Part 1: General information of informants}

The informants consist of 4 students, one female and three males. All are second year students of the Faculty of Business Administration, majoring in Management at Chiang Mai University. They were willing to provide detailed information and use photographs of their projects for publication. However, they preferred not to make public their names and faces.

\section{Part 2: Learning process/results}

The researcher applied the five-stage design thinking concept to develop the learning process of this course. The learning process in this class consists of 5 main phases with 11 steps. The learning process and results are reported as follows.

\section{Phase 1:}

Step 1: Teacher assigns semester project 'Develop an Innovative Business Project'.

Step 2: Students research/brainstorm for 'product idea' and develop 'product prototype'.

As the instructor assigned the student a semester project entitled 'Develop an Innovative Business Project,' this group of 4 members brainstormed and came up with 2 ideas. The first idea was smart eyeglasses which can be controlled by smart watch. However, the team decided not to work on this idea since they believed they could not afford to initiate such advanced technology. 
Another idea was a smart robot vacuum which is a robot vacuum cleaner controlled by application on a mobile phone. The team discovered this idea by talking to their friends who stay in dormitories and discussed about what products they want to ease their lifestyle. Afterwards, they made a list of innovative product functions and developed a product prototype accordingly. The instructor's intention for this phase is to stimulate the students' cognitive ability and process skills by Interacting with situations that can lead to new ideas and concepts. In this phase, the students were encouraged to gather information, test their ideas, and construct explanations logically.

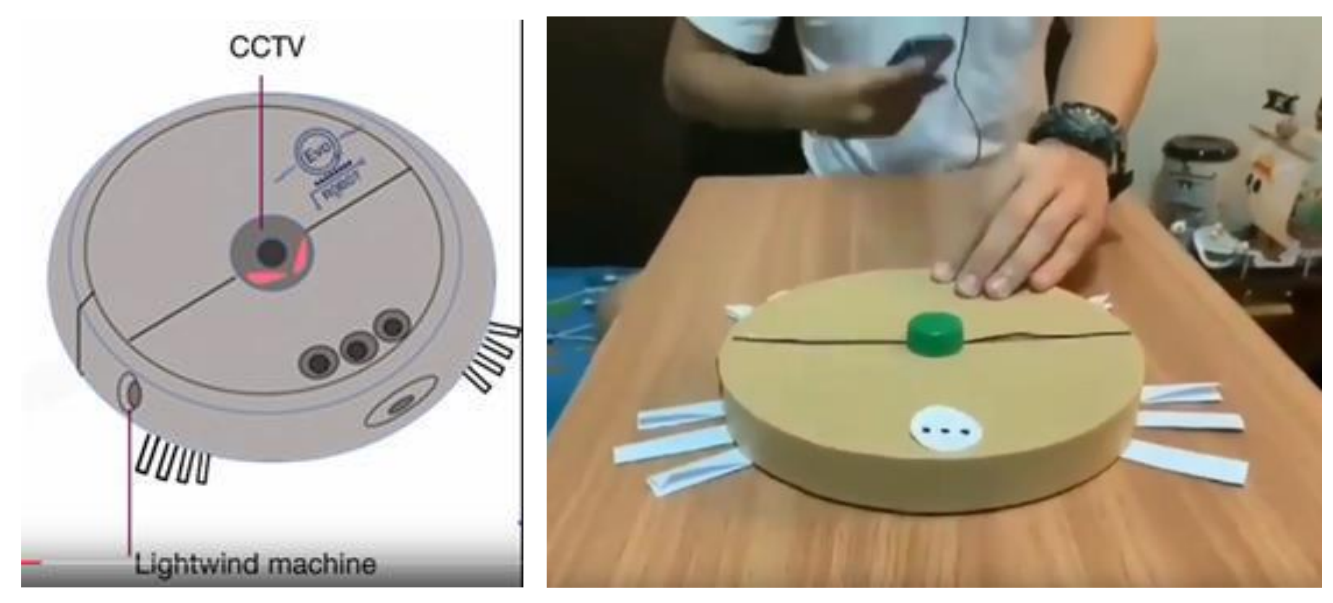

Figure 1. Prototypes of the team's robot vacuum cleaner.

\section{Phase 2:}

Step 3: Students present 'product idea' and 'product prototype' to the class.

Step 4: Class asks 'Devil's Advocate questions'.

Step 5: Students fix their product idea and product prototype.

In this phase, the students presented their product idea and product prototype, as well as the price of the product, to the class. Afterward, their classmates asked Devil's Advocate questions to the team. The question is, for instance, "What if a big corporate entity copies your product idea and manufactures it on a large scale to launch into the market? How would you compete with such a competitor?" In response to the Devil's Advocate questions, the students answered that they will register for a patent for their product before they reveal it to the market. The intent of this phase is to encourage students to develop their physical abilities and technical aptitudes by developing a physical product prototype and exercise their process skills by presenting their ideas and receive feedback from their classmates. The Devil's Advocate technique is added to sharpen the students' cognitive ability and process skills. Moreover, even the Devil's Advocate technique could be viewed as a harsh exercise where students in the course criticize other classmates' ideas, it could also be viewed as a strategy to provide suggestion constructively and rationally. As a result, this method could enhance the students' social capability.

\section{Phrase 3:}

Step 6: Students identify target customers and conduct a market survey.

Step 7: Students fix their product idea and product prototype. 
Then, the students identified target customers and conduct a market survey. Their target customers are the university students living in dormitories and have to clean their own rooms. The team brought their product prototype to demonstrate to their 30 target customers and ask for feedback. The major finding was that the product price was too high $(20,000$ Thai Baht), so the team decided to lower the price to 15,000 Thai Baht to meet the customers' willingness to pay. With this price, the business is still profitable. The instructor designed this phase to allow students to practice their content capability on creating valuable, relevant, and consistent content to attract the counterparty. In addition, the instructor also aims to cultivate problem solving ability to the students through this phase.
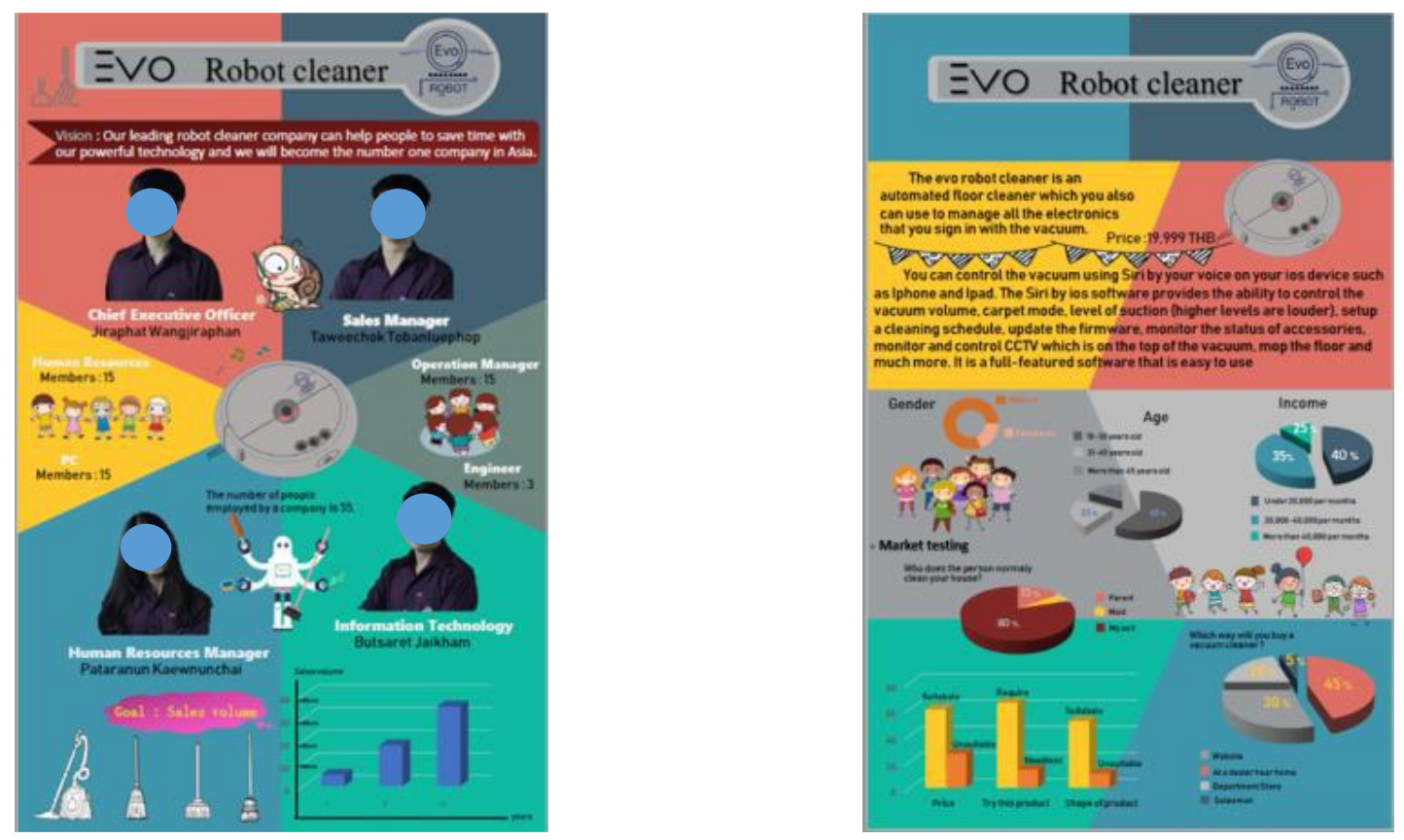

Figure 2. Market survey results.

Phase 4:

Step 8: Students develop 'Business Model'.

Step 9: Students present 'Business Model' to the class.

Step 10: Class asks 'Devil's Advocate questions'.

In this phrase, the team developed a business model starting from how and where to produce the product, how to finance their business and how to market the product. The importance of the assigned business model includes production, marketing, and financial parts. They also searched for necessary data such as elements of the products and their cost. In the marketing part, the students made a presentation on their target customers and strategies to attract target customers. The marketing analysis was based on the data from an earlier survey. For the production part, the team realized that they had neither the facilities nor the skills to produce the actual product prototype, so they searched and found the Fabrication Laboratory (Fab-Lab) located at the Faculty of Engineering in the same campus. Thenceforth, they contacted the Lab and the engineering students to co-develop their product prototype with them. After the team explained their product idea and business model to the engineering students, both parties agreed to work on this project together. The engineering students worked on the technical production part and the 
business students were responsible for the business areas such as financing and marketing. For the financial part, the students researched data on potential source and use of fund. Subsequently, the team presented their business model to the class and their classmates asked them Devil's Advocate questions. The noteworthy question was how they would manufacture their product for a commercialize scale. The answer was that after the prototype was completed from the Fab-Lab, the team will use it to hire an external factory to produce the product for mass production. In this phase, the students had an opportunity to practice their process and system skills again by reviewing their business idea and to find the most suitable solution. Furthermore, they repeat their practices on constructing content and social capability through the recurrence learning process. The student also develops efficient resource management attributes by gathering and analyzing data as well as consideration about the efficiency of resource management.

\section{Phase 5:}

Step 11: Learning reflection

After the final presentation, the instructor asked the students to reflect on their learning outcome based on the workforce 4.0 attributes. The results are shown in the following parts.

\section{Part 3: Degree of workforce 4.0 attributes: Before vs After working on the project.}

To retrieve the measurable degree of their workforce 4.0 attributes comparing before and after working on this project, the researcher applied a structured questionnaire to collect the students' feedback. The students scored their feedback on a 5-scale assessment form. The significance finding was that before they worked on the project, the students' highest degree of attribution was process skill (3.0/5.0). After finishing the project, the highest degree of attributes were social capabilities (5.0/5.0) and process skills (5.0/5.0). When comparing the differences in degree of attributes before and after working on the project, the top improvement was their technical aptitude (3.5/5.0). The results are shown in the figures below.

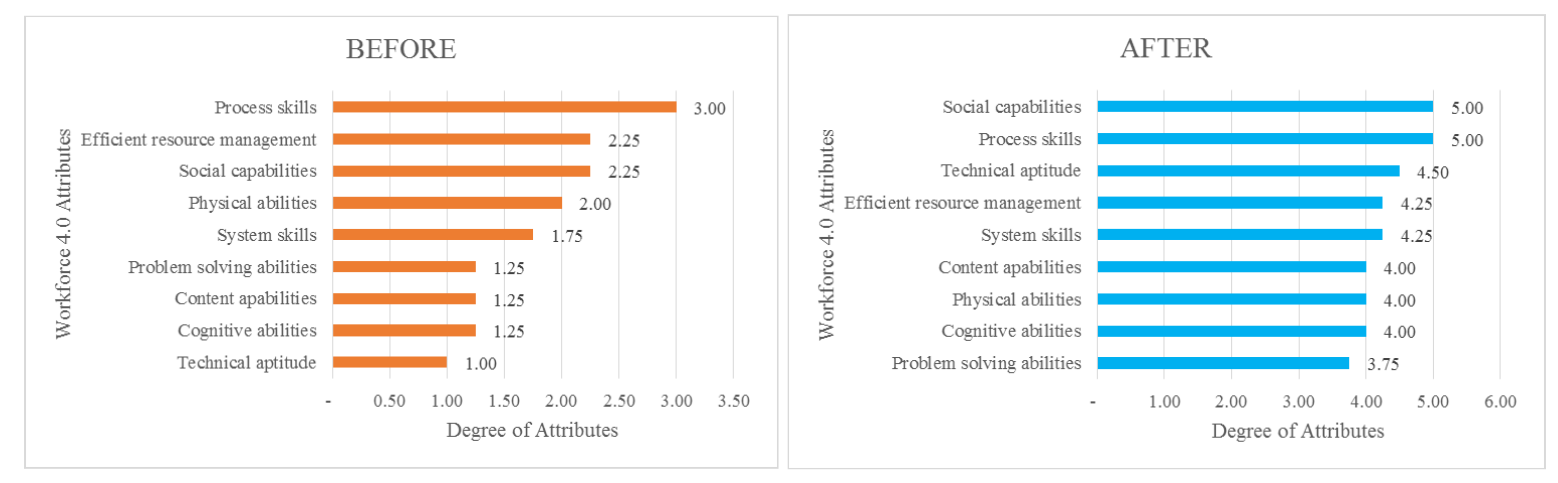

Figure 3. Degree of workforce 4.0 attributes: Before vs After working on the project.

Note: Interpretation of degree of effectiveness 4.50-5.00 = Highest, 3.50-4.49 = High, 2.50-3.49= Medium, 1.50-2.49 = Low, 1.00-1.49 = Lowest 


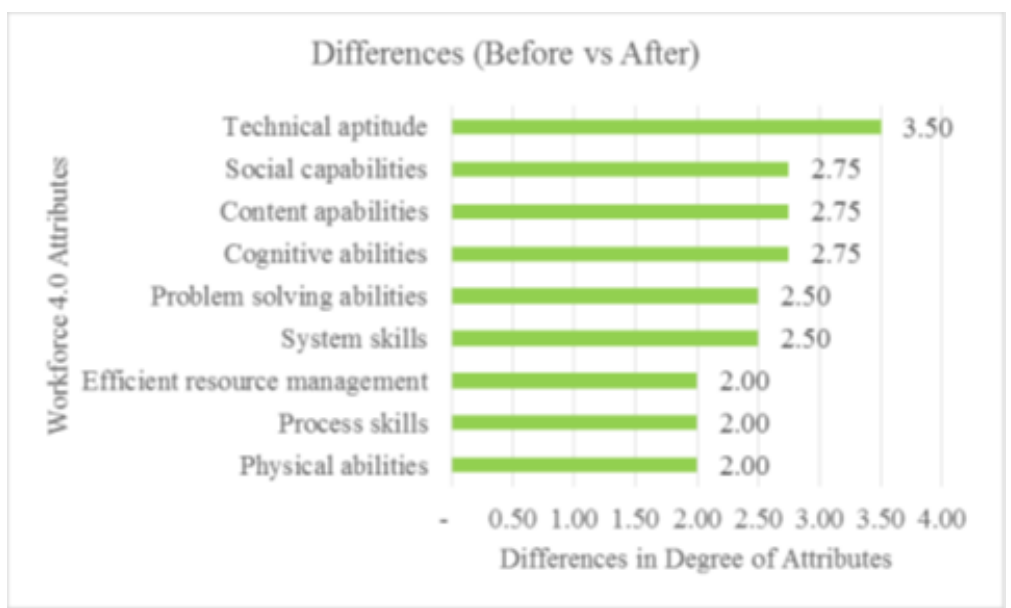

Figure 4. Differences in degree of workforce 4.0 attributes: Before vs After working on the project.

\section{Part 4: Reflections}

The students reflected that by working on this Business-Engineering Integration Project, they realized that even though they, as business students, are low in production/technical skills, they were able to collaborate with people outside of their specialized field to accomplish the project.

We (business students) realize that we do not have engineering skills, but we know how to collaborate with them (engineering students). Thank you for encouraging and guiding us to go out and ask for collaboration with external resources. Student A.

The students also learned that soft skills such as social capabilities are important for the present workforce.

Now I know the importance of connecting with target customers to learn their preferences. To do business successfully, we cannot expect that the customers will like our product simply because we, producer, believe our product is great. We have to find the answers from the real people. Student B.

Another significant finding was that students learned to think critically and logically through the Devil's Advocate questioning technique.

At first I did not know how to think critically, I just enjoyed listening to my friends' presentations and thought that all of the ideas were interesting. However, when the teacher instructed us to ask Devil's Advocate questions, I started to see the gaps in their ideas and wanted to help them by asking critical questions that they might have overlooked. At the end, we all benefited from those questions. Student C.

The students suggested using co-class teaching and continuous project to the higher-level classes.

For me, I truly developed workforce 4.0 attributes in myself through this project. It would be ideal if the two faculties arrange a co-class teaching between engineering and business to enhance both hard and soft skills of both sides. In addition, it would be beneficial for the students to continue the same type of project to the higher-level classes. Student D. 


\section{DISCUSSION AND CONCLUSION}

This case study showed that the students gained workforce 4.0 attributes through their business-engineering integration project. There are 3 significant lessons learned from this case study. The first lesson learned, project-based learning pedagogy is effective in cultivating practical knowledge to the students. In this case, the instructor organized the class into 5 phases. In each phase, the students learned by doing research and brainstorming among the team members. The instructor's role was to provide clear instructions and give guidance for them to research further on their own. This result is in line with other research indicating that the students involved in project- based learning groups received better academic achievement and maintaining of knowledge than being in a traditional teaching group (Karaçalli and Korur, 2014). The second lesson learned, workforce 4.0 attributes consist of hard skills and soft skills. Even though the hard skills such as technical aptitude and content capability are important, the soft skills such as social capability and resource management are necessary. This finding is in accordance with the research entitled 'Employability Skills That Recruiters Demand' by Krishna (2014), which reported that the employability skills that employers demand were hard skills that are essential to accomplish a task, and soft skills, which are the qualities associated with individual character or attitude. The last lesson learned is cross-disciplinary learning method is essential for developing workforce 4.0 attributes. This lesson learned supports the research findings of Letterman and Dugan (2004) that stated collaborative teaching can stimulate student enthusiasm and inquiry, and enhance interdisciplinary learning. In conclusion, this case study could be adopted and applied in the higher education system to foster workforce 4.0 attributes for students.

\section{ACKNOWLEDGEMENTS}

This research was conducted at Faculty of Business Administration and Fab-Lab, Faculty of Engineering, Chiang Mai University. The authors would like to thank the students from both Faculties for their contribution of information. We also deeply appreciate Assistant professor Traci Morachnick from the Faculty of Business Administration for her kind expertise to edit this paper.

\section{REFERENCES}

Australian Curriculum. (2020). Personal and social capability. Retrieved from https://www. australiancurriculum.edu.au/f-10-curriculum/general-capabilities/personal-and-socialcapability/

Awasthi, E.G. (2010). Social skills \& system skills. Retrieved from https://www.slideshare.net/ eshaawasthi1/social-skills-4491559.

Bell, S. 2010. Project-based learning for the $21^{\text {st }}$ century: skills for the future. Journal of Educational Strategies, 83(2):39-43.

Bird, K. (2018). What is resource management? Association for project management. Retrieved from https://www.apm.org.uk/blog/what-is-resource-management/

Content Marketing Institute. (2020). What is content marketing? Retrieved from https:// contentmarketinginstitute.com/what-is-content-marketing/ 
Dam, R.F., \& Teo, Y.S. (2020). 5 Stages in the design thinking process. Retrieved from https:// www.interaction-design.org/literature/article/5-stages-in-the-design-thinking-process.

Deloitte. (2020). 2018 skills gap in manufacturing study. Retrieved from https://www2.deloitte. $\mathrm{com} /$ us/en/pages/manufacturing/articles/future-of-manufacturing-skills-gap-study.html

Doyle, A. (2019). Important technical skills with examples. Retrieved from https://www. thebalancecareers.com/technical-skills-list-2063775.

Faculty of Business Administration, Chiang Mai University. (2019). Communication for business Results (703322) syllabus.

George Mason University. (2019). Teaching strategies. Retrieved from http://www.gmu.edu/ resources/facstaff/part-time/strategy.html

Hartwig, R.T. (2019). 7 Steps to analyze a problem -The devil's advocacy technique. Retrieved from http://www.ryanhartwig.com/7-steps-to-analyze-a-problem-the-devils-advocacy-technique/

Indeed Career Guide. (2020). Problem-solving skills: definitions and examples. Retrieved from https://www.indeed.com/career-advice/resumes-cover-letters/problem-solving-skills

Institute for Inquiry. (2006). Process skills definition in Fundamentals of inquiry facilitator's guide. San Francisco: Exploratorium.

Interaction Design Foundation. (2020). Design thinking. Retrieved from https://www.interactiondesign.org/literature/topics/design-thinking

Johnson, P. (2020). Automation and employment: how universities must respond to Industry 4.0. Retrieved from https://www.thedrum.com/opinion/2020/01/30/automation-and-employmenthow-universities-must-respond-industry- 40

Krishna, M. (2014). Employability skills that recruiters demand. IUP Journal of Soft Skills, 8(3): 5055.

Karaçalli, S. \& Korur, F. (2014). The effects of project-based learning on students' academic achievement, attitude, and retention of knowledge: the subject of 'electricity in our lives.' School Science and Mathematics, 114(5): 224-235.

Letterman, M.R. \& Dugan, K.B. (2004). Team teaching a cross-disciplinary honors course: preparation and development. College Teaching, 52(2): 76-79.

Michelon, P. (2006). What are cognitive abilities and skills, and how to boost them? Retrieved from https://sharpbrains.com/blog/2006/12/18/what-are-cognitive-abilities/

Pathak, V., Jena, B., \& Kalra, S. (2013). Qualitative research. Retrieved from https://www. ncbi.nlm.nih.gov/pmc/articles/PMC3757586/

Stackpole, B. (2019). Training today's workforce to fill the skills gap. Retrieved from https:/www.automationworld.com/home/article/13320074/training-todays-workforce-to-fillthe-skills-gap

U.S. Office of Personnel Management. (2020). Physical ability tests. Retrieved from https://www.opm.gov/policy-data-oversight/assessment-and-selection/other-assessmentmethods/physical-ability-tests/

Workforce Blueprint. (2017). What is required for Workforce 4.0? Retrieved from http://www.workforceplanningtools.com.au/what-is-required-for-workforce-4-0/ 